\title{
Performance of LED street lights in hot environments
}

\author{
R. Saraiji, A. Harb \& M. O. Hamdan \\ United Arab Emirates University, United Arab Emirates
}

\begin{abstract}
Solid-state LED street lights present significant benefits to street light operators as well as drivers and pedestrians. Questions remain, however, about their performance in high temperature conditions. This paper explores the performance of LED street light in one of the hottest regions in the world.

Two LED street lights were installed in an actual street in the city of Al Ain, United Arab Emirates. The street was closed to the traffic and illuminance measurements were taken daily every 10 minutes throughout the summer of 2010. Temperature and relative humidity values were also taken inside the two light fixtures as well as outside the fixtures. The summer of 2010 had significantly high temperatures with one week in July reaching maximum ambient temperatures of $53^{\circ} \mathrm{C}$.

This paper shows the Lux levels as well as the temperature and relative humidity data acquired in the field. Results show fairly stable light levels throughout the summer. The Lux levels did not change by more than $10 \%$ throughout the summer.
\end{abstract}

Keywords: LED, solid-state lighting, street light, roadway lighting.

\section{Introduction}

Solid-state (LED) street lights present significant benefits to street light operators as well as to drivers and pedestrians alike. However questions remain on their performance in high temperature conditions. Whereas, many studies have reported the relationship between junction temperature and luminous flux on laboratory conditions, few studies were made on site under real conditions.

In recent decades, numerous papers have analyzed the LED (solid-state lighting) thermal challenge $[1,6]$. The LED thermal challenge is a bottleneck 
that limits the stability, reliability, and lifetime of LEDs. While the luminous efficiency and light output of these devices continue to increase, the present day values still require that multiple die be used to produce enough light to replace conventional general illumination sources. With the use of large LED arrays, it is possible to generate a large heat loads at the system level which can cause challenges for overall heat dissipation, especially when passive cooling is used. The large array with passive cooling techniques leads to elevated LED die temperatures, which have been linked to lower quantum efficiencies, shorter lifetimes, emission wavelength shifts and, catastrophic device failure [1-6]. A heat flux from a $900 \mu \mathrm{m}^{2}$ high brightness LED chip, has already reached approximately $125 \mathrm{~W} / \mathrm{cm}^{2}$ [3] which is considered relatively high heat flux and comparable to heat generation in integrated circuits.

In general, nearly $90 \%$ or more of the thermal energy is directly dissipated from the LED die through conduction as opposed to radiation as seen in incandescent sources [7]. Hence, the LEDs packaging materials are critical for thermal dissipation since it affects the thermal resistance. At the system level, convection to the surrounding is the main scheme for thermal dissipation which is attained through natural or active means. Therefore in order to increase the luminous flux for compact high power LED arrays, thermal packaging engineer must focus on providing the highest convective heat transfer coefficients (within reasonable energy constraints) while improving the packaging design. In literature, several LEDs thermal management solutions are employed such as flat heat pipes [8], forced air convection, and liquid cooling which is vital to the development of high power compact LED arrays. While much attention is given to maintaining a specific temperature limit, thermo-mechanical effects also play a large role in array reliability and must be investigated as well. The stress in the die can be considerably different when mounted to Copper versus Aluminium heat sinks. It is reported in literature that residual compression is found in $\mathrm{GaN}$ die [9]. This is critical for LEDs design since the compressive stresses affect the band gap and the light output from the LED die.

From literature, it is clear that the LEDs package materials must satisfy numerous requirements, including high thermal conductivity, high mechanical strength and stiffness and, high chemical inertness [10].

Conventionally LEDs are driven in the amplitude mode (AM) by direct current or in the pulse-width-modulation (PWM) mode by pulsating current [11, 12]. Despite the apparent ease of operating the LEDs with direct current, it is challenging to dim the LEDs given the high sensitivity of the forward current to a change in the forward voltage owing to the device's small dynamic resistance, where a very precise regulation of the forward voltage is required for a stable luminous output. It is also well documented that a direct change of the forward current can alter the emitted wavelength or color of the LEDs at different luminosity levels. In contrast, dimming is conveniently achieved with PWM by controlling the pulse duration, thus avoiding direct adjustments of the current amplitude and consequently high colour stability is attained. However, this is possible at the sacrifice of luminous efficacy, given that the LEDs have to 
operate at larger current amplitude during the pulse duration for the same average current as the AM case. This is due to the tendency of the luminous output of LEDs to saturate at large forward current. In short, the conventional driving techniques are beneficial in some aspects but lacking in others.

PWM dimming operation consists of switching on and off the LED light, making it flicker. If this flickering is performed fast enough, the human eye can only perceive a decrease in the luminous output due to the stroboscopic effect. The human eye does not perceive the flickering if the dimming frequency is at least $50 \mathrm{~Hz}$, but the recommended minimum frequency is $200 \mathrm{~Hz}$ so moving objects do not seem to be still. Three main methods for PWM dimming operation were identified by Yuan et al. [12].

Long et al. [13] tested a 50 Watt street light in a street in China, using a 9 LED module with an adaptive driver. The heat sink temperature reached $58^{\circ} \mathrm{C}$ after 60 minutes of operation. After three months of operation Long et al. did not detect any changes in light levels and the junction temperature was in the range of less than $78^{\circ} \mathrm{C}$ measured by an IR thermometer.

In this project, two 101 watt LED Street light driven by PWM drivers, were tested in the field in the city of Al Ain, United Arab Emirates during the hot summer season. The city is known for its extreme hot climate. Two lighting units were mounted in relatively low use street which has minimum lighting from the surrounding, in order to isolate the effect of the surrounding lighting systems.

The objective of the experiment is to test the stability of LED street lights under hot environment from an illumination point of view. The experiment described thereof is not about the effect of temperature on the life of the LED.

The manuscript presents two sets of data which were collected in (a) the laboratory and (b) the field. The collected data include internal and external lighting fixture temperature and relative humidity $(\mathrm{RH})$ recorded over a period of time as well as illumination levels.

\subsection{Thermal measurements}

The temperature and relative humidity $(\mathrm{RH})$ data is collected using data recorder from ACR "Smart Reader Plus 2". The data were recorded every 10 minutes which allows 10 months period of data collection.

\subsection{Laboratory measurements}

A test was done in the laboratory at room temperature conditions. The collected data is presented in Figure 1. The temperature data logger was installed in the LED light box and was tested on June $15^{\text {th }}$ at 7 am. A test was conducted from 9:15 am to 4:50 pm which is shown in Figure 1. The results show that the temperature went up from 24.8 to $41^{\circ} \mathrm{C}$ in less than two hours. The data recorder collected data inside the light box till 4:50 pm where maximum temperature inside the box reached around $42^{\circ} \mathrm{C}$. 


\subsection{Data collected in the field}

Two LED street lights were installed on a 10 meter high pole. Each street light was 101 watt including the LED drivers. There were 84 LEDs in each fixture with each LED rated at 1 watt. The data collected in the field is presented in the next subsections.

Temperature and relative humidity data loggers were programmed to take measurement every 10 minutes and were mounted in the following locations as illustrated in Figure 2:

1. Inside the pole but close to the base (this value is considered the ambient temperature)

2. Inside light fixture number 1 in the LED-driver's compartment

3. Inside light fixture number 2 in the LED-driver's compartment

4. On the side walk.

The ambient temperatures throughout the test period are presented in Figure 3. The maximum temperature during this period was $54^{\circ} \mathrm{C}$ which occurred on July $17^{\text {th }}$.

The average and the maximum temperature daily values inside the two light fixtures were compared to the ambient temperature; the results are shown in Figure 4.

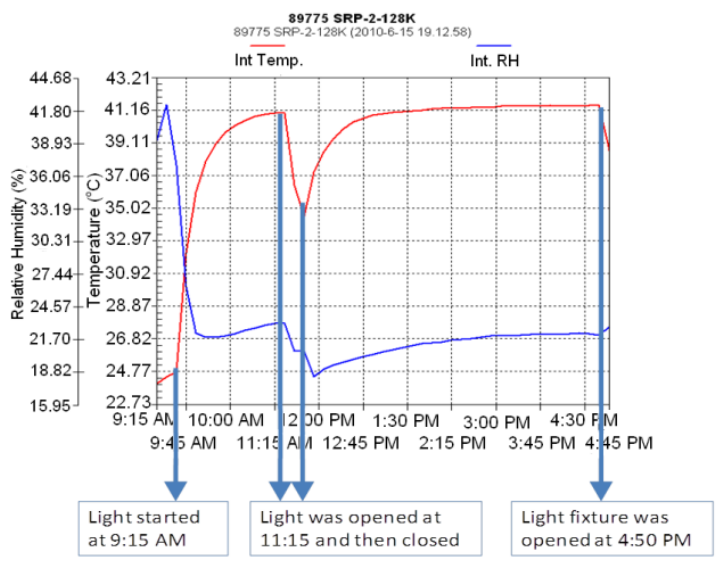

Figure 1: The temperature inside the LED light fixture recorded on June 15th from 9:15 am till 4:50 pm. The fixture was opened at 11:15 am for 10 minutes period. Room temperature conditions. 


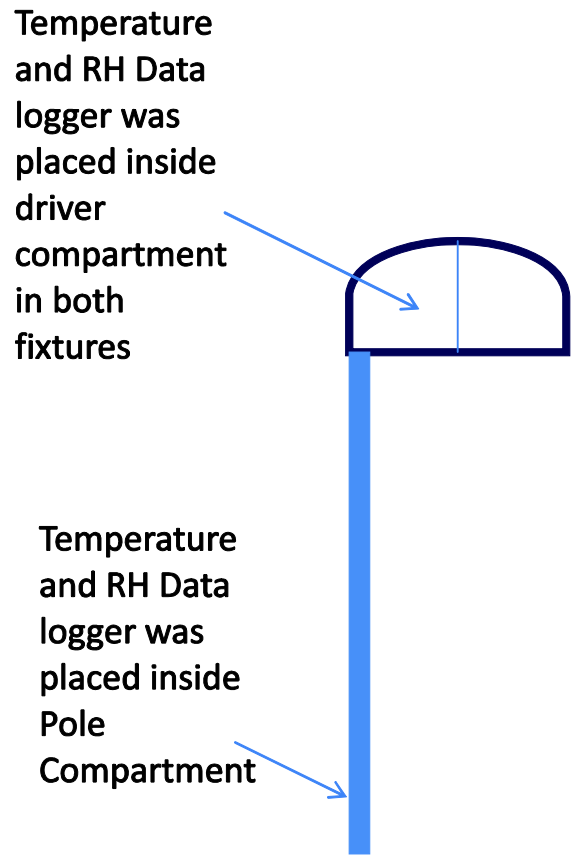

Figure 2: Locations of the temperature and relative humidity data loggers.

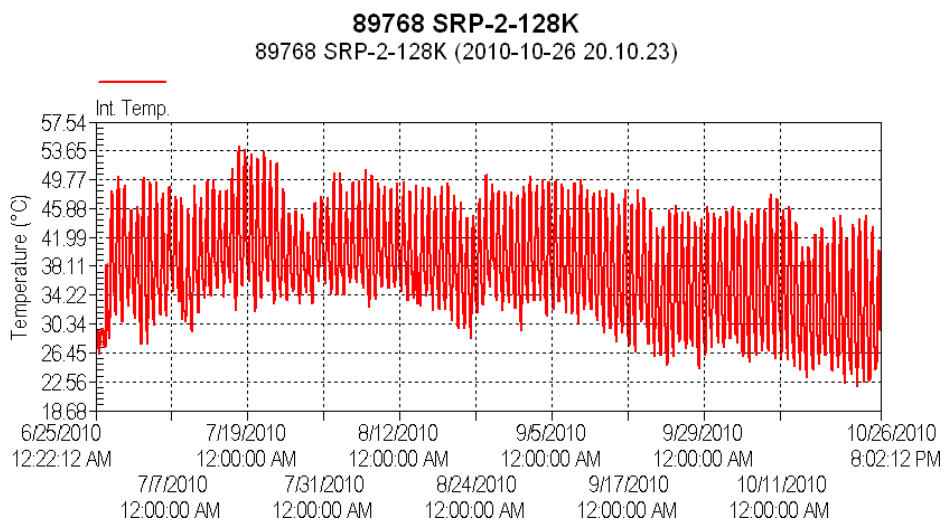

Figure 3: Ambient temperature throughout the summer. Site conditions. 
152 Lighting in Engineering, Architecture and the Environment

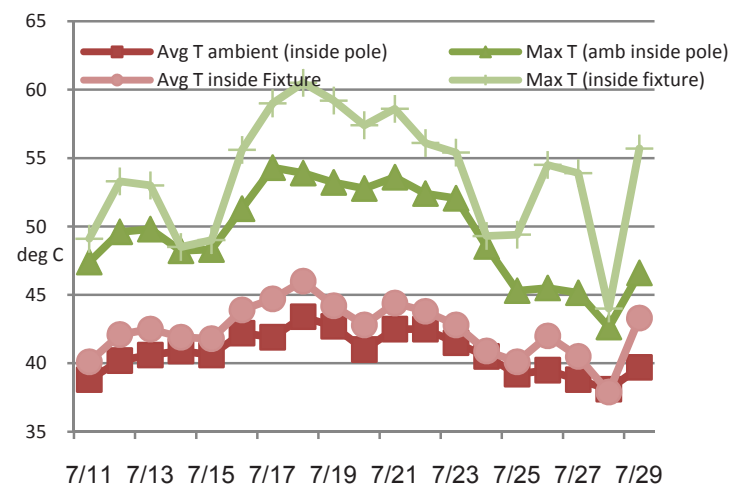

Figure 4: Comparison between ambient temperatures and temperatures inside fixture 1 . Using average and maximum daily values.

As far as the temperature inside fixtures 1 and 2 the maximum temperature recorded inside fixture 1 was $60.5^{\circ} \mathrm{C}$. This temperature occurred during the daytime of July 18 . The maximum temperature during the night was $46^{\circ} \mathrm{C}$. On the other hand, the maximum temperature recorded inside fixture 2 was $61.1^{\circ} \mathrm{C}$ which occurred during the daytime, while the maximum temperature inside fixture 2 during the night was $46^{\circ} \mathrm{C}$. The dynamic of temperature variation inside the light fixtures for one day (June $30^{\text {th }}$ ) is illustrated in Figure 5. The figure shows how the temperature inside the fixture experiences a sudden rise after the lights are turned on and a sharp drop when the LEDs are turned off.

For most of the day, the temperature inside the fixtures is higher than the ambient temperatures. Temperatures inside the fixtures during the night were in the range of $38-44^{\circ} \mathrm{C}$. The minimum and maximum as well as the average temperatures inside fixtures 1 and 2 are shown in Figure 6 through to Figure 8.

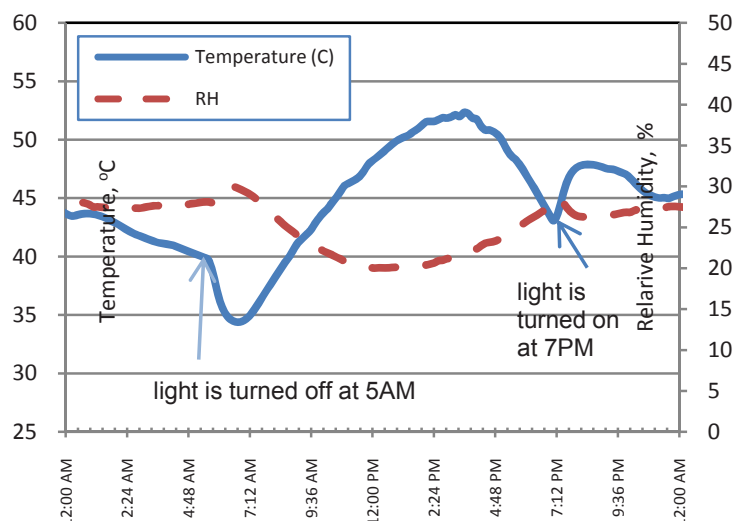

Figure 5: $\quad$ Temperature dynamic inside fixture 2 in one night. 


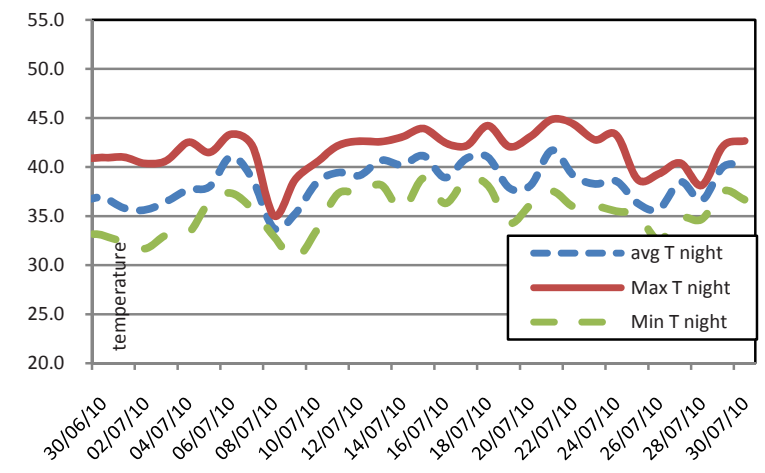

Figure 6: Night temperatures values in degree Celsius inside fixture 1 for the month of July.

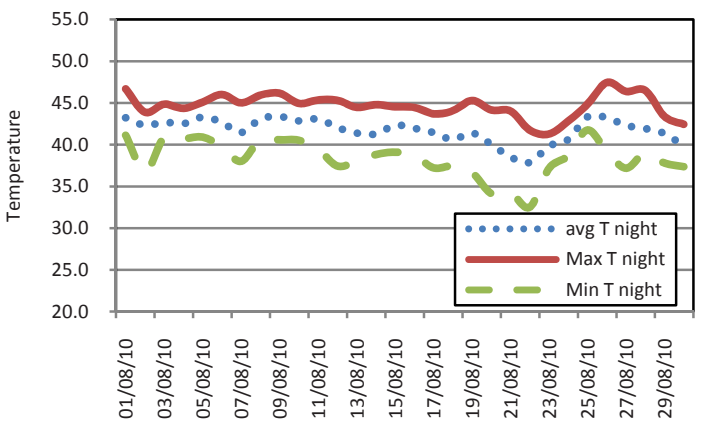

Figure 7: Night temperature values in degree Celsius inside fixture 1 for the month of August.

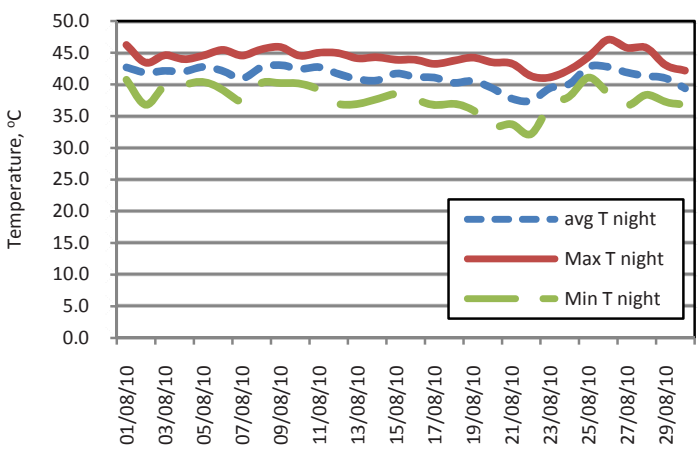

Figure 8: Night temperature in degree Celsius inside fixture 2 during the month of August. 


\section{Illumination results}

An isolated street in one of the university campuses in Al Ain, United Arab Emirates, was used as the test site. The street was closed to traffic. The city has extremely hot and dry conditions during the summer months. Two 10-meter high poles were used with a spacing of 50 meters on this 7.3 meter wide street. Eight illuminance sensors were used; three sensors were along the lateral direction of fixture 2, three more sensors were placed halfway along symmetry lines, while 2 sensors were used for fixture 1. The sensors were dusted off daily using compressed air. The top view of the setup is shown in Figure 9. The lights were turned on at $7 \mathrm{pm}$ and off at $5 \mathrm{am}$. Lux values were collected every 10 minutes including daytime. Daytime Lux levels gave an indication of sky conditions during the day whether cloudy or sunny. The spikes in the light levels indicate the start and the end of daylight. The Lux levels at point 1-1 ranged from 19 to 21 Lux and are shown in Figures 10 and 11. The average Lux levels at point $1-1$ and 2-1 were compared to the average temperature inside fixture 2 during the night. The results are shown in Figures 12 and 13, respectively.

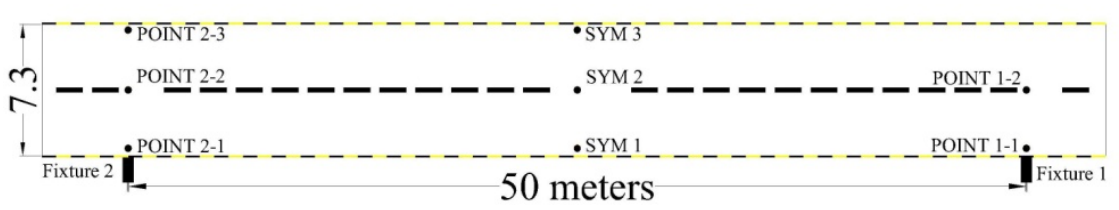

Figure 9: Top view of the street showing location of poles and location of illuminance sensors.

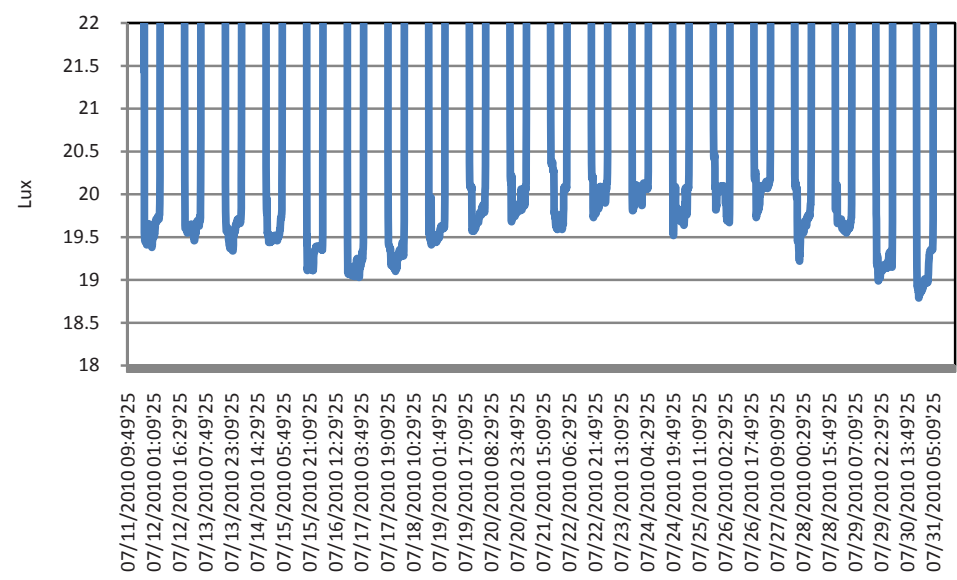

Figure 10: $\quad$ Lux Levels for point 1-1 -July. 


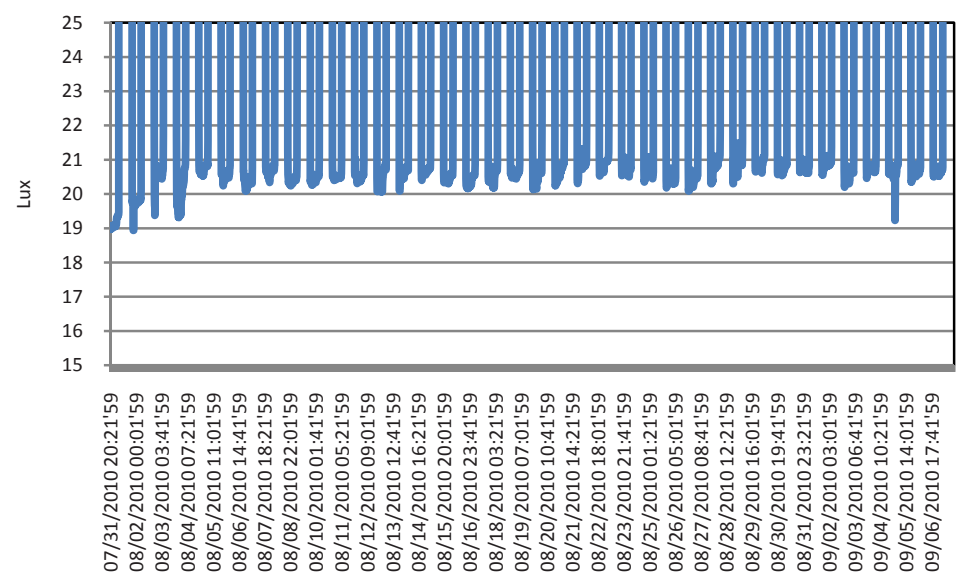

Figure 11: Lux levels for point 1-1 August through to September $7^{\text {th }}$.

For three weeks in July, the hottest period during the test, the average Lux at point 1-1 was 19.65 with a standard deviation of $1.5 \%$. The maximum Lux level for that point during the month of July was 20 while the minimum level was 19.1 Lux. The summary of temperatures throughout the summer is shown in Table 1.

The average night time illuminance at point $1-1$ versus the average night time temperature inside fixture 1 during one night (July 31) was plotted in Figure 14. A regression fit can be obtained and the drop in light levels with increase in temperature inside the driver compartment is clear. This drop is, however, very small.

The luminance map of the street was taken using a CCD imaging camera. The result shows an average luminance of $1.1 \mathrm{~cd} / \mathrm{m}^{2}$ with an average to minimum uniformity ratio of 1.6 .

We were able to monitor the voltage and current for a limited number of days for 1 LED from 1 light fixture. The on-site recorded duty cycle of the PWM signals are in line with the value measured in the lab for full intensity (without dimming); thus we can easily conclude that no dimming has occurred during all these measurements. This is an important observation to conclude that any drop in Lux levels is caused by increase in temperature and not due to the dimming of LED by the driver.

Table 1: $\quad$ Average daily temperature values for the summer from $14^{\text {th }}$ June through Oct $26^{\text {th }}$.

\begin{tabular}{|l|c|c|c|c|c|}
\hline & Maximum & Mean & Minimum & Range & Std deviation \\
\hline Ambient & 54.30 & 37.13 & 21.02 & 33.29 & 6.80 \\
\hline Inside fixture 2 & 61.09 & 41.27 & 22.71 & 38.39 & 6.43 \\
\hline Inside fixture 1 & 60.53 & 41.17 & 22.97 & 37.56 & 6.47 \\
\hline
\end{tabular}


156 Lighting in Engineering, Architecture and the Environment

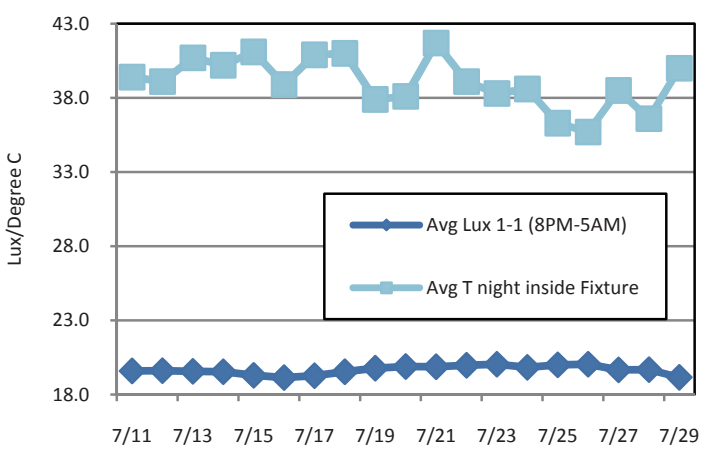

Figure 12: $\quad$ Lux levels for point 1-1 and temperatures inside fixture 1.

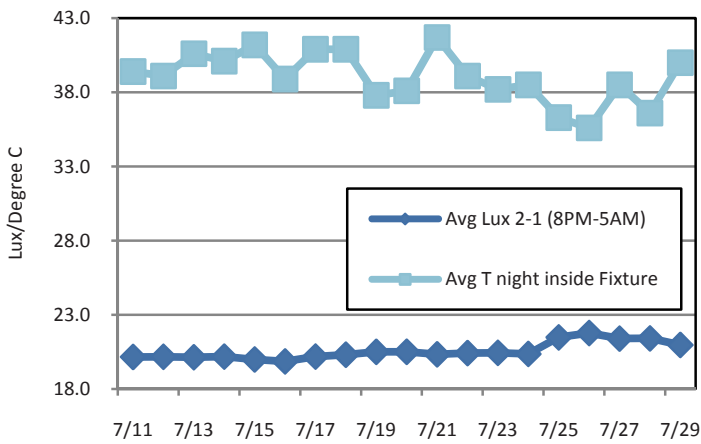

Figure 13: Average daily Lux levels at point 2-1 relative to the night temperature inside fixture 2 .

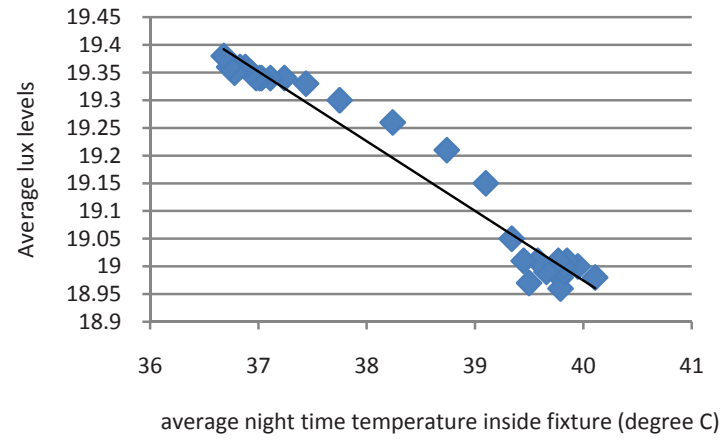

Figure 14: Average night time Illuminance at point 1-1 versus average night temperature inside fixture- night of July 31. 


\section{Conclusion}

The following conclusions can be made:

- The LED light levels of the LED street light were fairly stable throughout the hot days of the summer.

- For fixture 1 and 2 the average nightly temperature inside the fixture ranged from $35-43^{\circ} \mathrm{C}$. The average temperature inside the fixtures for the month of August was around $41^{\circ} \mathrm{C}$.

- Lux levels did not change by more than $10 \%$ during the test period.

- The average Luminance of the street was $1.1 \mathrm{~cd} / \mathrm{m}^{2}$, with a uniformity ratio (average Luminance over minimum Luminance) of 1.6.

- No electrical dimming has occurred in all on-site measurements.

Further studies need to be made to test the Lux levels at cold days and, the Lux levels over several years to test lumen depreciation. Given the fact that the heat sinks of different street light from different manufacturers have different designs, caution must be taken not to extend the conclusion of this test into all LED street lighting products.

\section{Acknowledgement}

The authors would like to thank the iGuzzini Lighting Company for sponsoring this project.

\section{References}

[1] Narendran, N. and Y. Gu, "Life of LED-based white light sources", IEEE/OSA Journal of Display Technology, 1(1): p. 167-170,2005.

[2] Narendran, N., Y. Gu, J.P. Freyssinier, H. Yu, and L. Deng, "Solid-state lighting: Failure analysis of white LEDs", Journal of Crystal Growth, 268: p. 449-456,2004.

[3] Narendran, N., Y. Gu, and R. Hosseinzadeh, "Estimating junction temperature of high-flux white LEDs", Proceedings of SPIE -The International Society for Optical Engineering, San Jose, CA, United States: The International Society for Optical Engineering, Bellingham, United States, 2004.

[4] Arik, M., Becker, C., Weaver, S. and Petroski, J., "Thermal Management of LEDs: Package to System", Proceedings of SPIE - The International Society for Optical Engineering.. San Diego, CA, United States: International Society for Optical Engineering, Bellingham, WA982270010, United States, 2004.

[5] Arik, M, Petroski, J. and Weaver, S., "Thermal Challenges in the Future Generation Solid State Lighting Applications: Light Emitting Diodes", ASME/IEEE INTERPACK 2001 Conference, Kauai, Hawaii, July 2001.

[6] Garg, J., Arik, M., Weaver, and Saddoughi, S., "Micro fluidic Jets for Thermal Management of Electronics", ASME Heat Transfer/Fluids Engineering Summer Conference, Charlotte, NC, 2004. 
158 Lighting in Engineering, Architecture and the Environment

[7] Petroski, J., "Spacing of high-brightness LEDs on metal substrate PCB's for proper thermal performance in Thermo-mechanical Phenomena in Electronic Systems" Proceedings of the Intersociety Conference, Las Vegas, NV, United States, 2004.

[8] Kim L., Choi J. H., Jang S. H., Shin M. W., "Thermal analysis of LED array system with heat pipe", Thermochimica Acta, Volume 455, Issues 12, 1, Pages 21-25,April 2007.

[9] Christensen A., Ha M., Graham S., "Thermal Management Methods for Compact High Power LED Arrays", Seventh International Conference on Solid State Lighting, Proc. of SPIE Vol. 6669, 66690Z, 2007.

[10] Jorge Garcia, Marco A. Dalla-Costa, Jesus Cardesin, Jose Marcos Alonso, and Manuel Rico-Secades "Dimming of High-Brightness LEDs by Means of Luminous Flux Thermal Estimation", IEEE Trans. Power Electronics, VOL. 24, NO. 4, pp. 1107-1114, April 2009.

[11] Loo, K.H. Wai-Keung Lun Siew-Chong Tan Lai, Y.M. Tse, C.K., "On the driving techniques for high-brightness LEDs", IEEE Energy Conversion Congress and Exposition (ECCE 2009), pp. 2059-2064 doi: 10.1109/ECCE $5315972,2009$.

[12] Yang Yuan, Song Zhenghua, and Gao Yong , "Design of High-Power White LED Drive Chip With Fully Integrated PWM Dimming Function", Symposium on Photonics and Optoelectronic (SOPO), pp. 1-4, doi: 10.1109/SOPO.2010.5504059,2010.

[13] Gacio, D., Alonso, J. M., Garcia, J., Campa, L., Crespo M. and RicoSecades, M., "High Frequency PWM Dimming Technique for High Power Factor Converters in LED Lighting", Twenty-Fifth Annual IEEE Applied Power Electronics Conference and Exposition (APEC), pp. 743-749, doi: 10.1109/APEC.2010.5433585, 2010.

[14] Long, X., Lio, R., Zhou, R., "Development of Street Lighting, SystemBased Novel High-Brightness LED Modules”, IET Optoelectron0, Vol. 3, Issue 1, pp.40-46, 2009. 